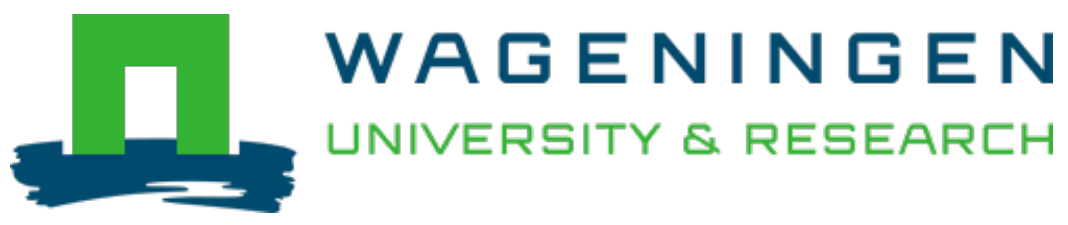

\title{
Ionization of glycans from alkali metal salt-impregnated paper
}

Talanta

Guo, Ping; Min, Ke; Luo, Wei; Huang, Si; Yang, Zihui et al

https://doi.org/10.1016/j.talanta.2021.122674

This publication is made publicly available in the institutional repository of Wageningen University and Research, under the terms of article $25 \mathrm{fa}$ of the Dutch Copyright Act, also known as the Amendment Taverne. This has been done with explicit consent by the author.

Article $25 \mathrm{fa}$ states that the author of a short scientific work funded either wholly or partially by Dutch public funds is entitled to make that work publicly available for no consideration following a reasonable period of time after the work was first published, provided that clear reference is made to the source of the first publication of the work.

This publication is distributed under The Association of Universities in the Netherlands (VSNU) 'Article $25 \mathrm{fa}$ implementation' project. In this project research outputs of researchers employed by Dutch Universities that comply with the legal requirements of Article $25 \mathrm{fa}$ of the Dutch Copyright Act are distributed online and free of cost or other barriers in institutional repositories. Research outputs are distributed six months after their first online publication in the original published version and with proper attribution to the source of the original publication.

You are permitted to download and use the publication for personal purposes. All rights remain with the author(s) and / or copyright owner(s) of this work. Any use of the publication or parts of it other than authorised under article $25 \mathrm{fa}$ of the Dutch Copyright act is prohibited. Wageningen University \& Research and the author(s) of this publication shall not be held responsible or liable for any damages resulting from your (re)use of this publication.

For questions regarding the public availability of this publication please contact openscience.library@,wur.nl 


\title{
Ionization of glycans from alkali metal salt-impregnated paper
}

\author{
Ping Guo ${ }^{\text {a,c }}$, Ke Min ${ }^{a}$, Wei Luo ${ }^{a}$, Si Huang ${ }^{a}$, Zihui Yang ${ }^{a}$, Ming Ma ${ }^{a}$, Shubin Liu ${ }^{b}$,

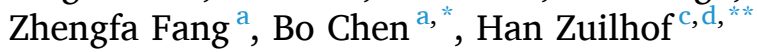 \\ ${ }^{a}$ Key Laboratory of Phytochemical R\&D of Hunan Province and Key Laboratory of Chemical Biology \& Traditional Chinese Medicine Research of Ministry of Education, \\ Hunan Normal University, Changsha, China \\ ${ }^{\mathrm{b}}$ Division of Research Computing, Information Technology Services, University of North Carolina, North Carolina, 27599, USA \\ ${ }^{c}$ Laboratory of Organic Chemistry, Wageningen University, Stippeneng 4, 6703, WE Wageningen, the Netherlands \\ ${ }^{\mathrm{d}}$ Department of Chemical and Materials Engineering, Faculty of Engineering, King Abdulaziz University, 21589, Jeddah, Saudi Arabia
}

\section{A R T I C L E I N F O}

\section{Keywords:}

Ambient ionization mass spectrometry

Paper spray ionization

Glycans analysis

Alkali metal adduct ions

\begin{abstract}
A B S T R A C T
Ambient ionization of glycans is simply and efficiently achieved by spraying from an alkali metal saltimpregnated paper surface. Monosaccharides, oligosaccharides and ring glycans easily form abundant alkali metal adduct ions, and give simple and clean high-quality mass spectra. The enhancement is specific for glycans, compared to a wide variety of non-glycan compounds present in a matrix. In addition, molecular weight of unknown glycans can be further identified based on the ion mass difference of various alkali metal adduct ions from a certain compound when using a mixed salt-impregnated paper containing five cation salts. Successful determination of glycans and glycoconjugates in plant extracts, honey, blood and urine demonstrates the practicability of this approach to complicated matrices, especially biological matrices.
\end{abstract}

\section{Introduction}

Ambient ionization mass spectrometry (AIMS) has been rapidly developed because of its typical advantages such as real-time, rapid as well as high-throughput for analysis of samples with no need of chromatographic separation or sample preparation, and multiple AIMS sources have been proposed [1]. To further improve AIMS performance, different strategies such as chemical derivatization, hyphenating AIMS with ion mobility spectrometry, chemical tagging, etc., have been advocated [2].

Paper spray (PS) ionization [3] is the simplest ionization mode of AIMS and a routine ionization source [4]. As the spray ionization from paper matrix, paper characteristics significantly affect the performance of PS-MS, e.g. selectivity, sensitivity, and ionization efficiency [5-12]. Recently, $\mathrm{a} \mathrm{Ag}^{+}$adduction strategy for the distinction of isomers, i.e., THC and CBD, by PS-MS was demonstrated by our group, which provided a compelling example of the idea that metal ion adduction is a powerful method to improve PS-MS performance [13].

For the application of AIMS in the life sciences, the direct ambient analysis of glycans is highly desirable. Focusing on AIMS of glycans, current PS-MS analysis does not have a good specificity, because of the formation of multi-ions such as [Glycan $+\mathrm{Na}]^{+}$, [Glycan $\left.+\mathrm{K}\right]^{+}$, [Glycan $+\mathrm{K}+\mathrm{O}^{+}$, [Glycan $\left.+\mathrm{K}+2 \mathrm{O}\right]^{+}$, etc. [14]. Alternatively, direct analysis in real time (DART)-MS [15] and reactive desorption electrospray ionization (DESI)-MS [16] have also been tested. However, the detectable range of molecular weight for DART and selectivity to glycans for DESI, respectively, were limited [17,18]. Therefore, other AIMS strategies for the analysis of glycans are needed. Based on the adduction phenomenon, the addition of controlled amounts of salts was proposed for DESI-MS analysis of neutral carbohydrates and steroids [19]. Although the detection limits are significantly improved by the addition of low concentrations of salts to the spray solvent, the tolerance toward such salts was limited (max. 10-100 $\mu \mathrm{M}$ concentrations in the spray solution), similar to ESI. In addition, little adduct formation and high ion suppression was observed when salt was present in the analyte and not in the spray solvent in DESI [20].

To further improve PS-MS performance for glycan analysis, in the current work we first introduce a simple alkali metal salt-impregnated paper spray MS (SIPS-MS) approach to the analysis of neutral glycans, including monosaccharides, oligosaccharides, and ring glycans, such as cyclodextrins. After a stepwise introduction of the method, we outline the formation of abundant alkali metal-glycans adduct ions, and

\footnotetext{
* Corresponding author.

$* *$ Corresponding author. Laboratory of Organic Chemistry, Wageningen University, Stippeneng 4, 6703, WE Wageningen, the Netherlands.

E-mail addresses: dr-chenpo@vip.sina.com (B. Chen), han.zuilhof@wur.nl (H. Zuilhof).
} 
demonstrate its application for direct detection of glucose and glycoconjugates in plant extracts, honey, blood and urine, even in a complex biological matrix containing a series of non-glycan compounds.

\section{Experimental}

\subsection{Chemicals and materials}

Codonopsis pilosula and Panax ginseng extracts reference materials, standards of ribose, fructose, glucose, maltose, maltotriose, maltotetraose, maltopentaose, maltohexaose, maltoheptaose, rutin and quercetin were purchased from the National Institute of Food and Drug Control (Beijing, China). Neoagarooctaose, agarononaose and neoagarodecaose were purchased from Xibao Biotechnology Co. Ltd (Shanghai, China). $\alpha$-, $\beta$ - and $\gamma$-Cyclodextrin were purchased from Macklin Reagent (Shanghai, China). Cytosine, adenine, cysteine, leucine, cis-1,2-cyclohexanediol, trans-1,2-cyclohexanediol and tetrahydropyran-2-methanol were purchased from J\&K Chemicals. 3Fucosyllactose and 2 -fucosyllactose were purchased from Glycosci. Honey was purchased from Shanghai Guanshengyuan Bee Products Co. Ltd. Blood and urine samples were collected from the Hunan provincial disease control and prevention center in Changsha. Ethylene glycol and glycerol were purchased from Sinopharm Chemical Reagent Co. Ltd. HPLC-grade methanol was obtained from Tedia Inc. (Fairfiled, OH, U.S. A). Other reagents were of analytical grade. Water was prepared by a Millipore Milli-Q purification system (Millipore Crop. Bedford, MA, USA). The structures of all tested compounds in this study were shown in Table S1.

\subsection{Instruments and conditions}

PS-MS analysis was performed using a Micromass ZQ 2000 mass spectrometer (Manchester, UK). It was equipped with Quadrupole Mass Analyzer, MasslynxTM 4.0 data system software, high voltage power supply and A XYZR moving plate. The positive ion mode was selected to obtain the MS profile. The extractor voltage was $3 \mathrm{~V}$, the RF lens voltage was $0.5 \mathrm{~V}$ and the source temperature was $105^{\circ} \mathrm{C}$. The sample volume applied onto the paper was $15 \mu \mathrm{L}$. According to the properties of the different compounds, the mass scan range, cone voltage and spray voltage were set at 100-2000 Da, 20-50 V, 3.0-3.5 kV, respectively.

A XYZR moving plate was made in-house for positioning the paper tip accurately relative to the MS cone. An isosceles triangular piece of chromatography paper was cut out to the dimensions: $10 \mathrm{~mm}$ (height) $\times 5 \mathrm{~mm}$ (base), and was held at a distance of 4-6 $\mathrm{mm}$ from the inlet of the mass spectrometer by an XYZR moving plate. The optimized high voltage was supplied directly to the paper triangles by copper clips to induce ionization. $15 \mu \mathrm{L}$ of the sample solution was applied to the paper triangle substrate for PS-MS chemical profile analysis.

\subsection{Preparation of standard solutions}

Single-standard solutions: when the tested compounds were a solid, $0.01 \mathrm{~g}$ of standard powder was extracted by $10 \mathrm{~mL}$ of methanol in an ice ultrasonic bath for $30 \mathrm{~min}$, except three substances namely $\alpha$-, $\beta$ - and $\gamma$-cyclodextrin, which were dissolved in $50 \%$ methanol/50\% water ( $\mathrm{v} /$ $\mathrm{v} /$ ). When it was a liquid, the compound was dissolved and diluted with methanol. In this manner, we obtained a series of stock standard solutions. Mixed Glycan standard solutions were obtained by accurately measuring out the appropriate amount of ribose, fructose, and maltose to one container and mixing them.

For PS-MS analysis, the concentration of stock standard solutions was $1000 \mu \mathrm{g} \mathrm{mL} \mathrm{m}^{-1}$. Working solutions for PS-MS analysis were diluted with methanol to $5 \mu \mathrm{g} \mathrm{mL} \mathrm{m}^{-1}$. For PS-MS quantitative analysis of glucose in the urine, ribose $\left(5.0 \mu \mathrm{g} \mathrm{mL}^{-1}\right)$ was used as the internal standard (I.S.). Stock standard solutions of glucose were diluted with methanol, and the concentrations for the calibration curve were 10,20,50, 100 and $150 \mu \mathrm{g} \mathrm{mL}{ }^{-1}$, respectively.

\subsection{Preparation of alkali metal salt-impregnated paper substrate}

For the preparation of alkali metal salt-impregnated paper, $\mathrm{Na}$ impregnation is given as example - the others are analogous. First, an aqueous solution of $0.01 \mathrm{~mol} \mathrm{~L}^{-1}$ alkali metal salt was prepared. Then the blank paper was placed into this salt solution and ultrasonication was applied for $50 \mathrm{~min}$ at room temperature; then the paper was removed with tweezers and dried in an oven at $100{ }^{\circ} \mathrm{C}$ for $12 \mathrm{~h}$, to obtain alkali metal salt-impregnated paper.

\subsection{Preparation of samples}

Plant extracts: $0.5 \mathrm{~g}$ of dried powder (Codonopsis pilosula and Panax ginseng) were extracted by $10 \mathrm{~mL}$ of methanol + water $(80: 20, \mathrm{v} / \mathrm{v})$ in an acoustic wave bath containing ice-water for $30 \mathrm{~min}$. Blood: $2-3 \mu \mathrm{L}$ of frozen whole blood was gently dropped onto blank paper and alkali metal salt-impregnated paper; then the paper was placed in a ventilated place at room temperature for $3 \mathrm{~h}$. Urine: method 1: $2-3 \mu \mathrm{L}$ of frozen whole urine were placed onto blank paper and alkali metal saltimpregnated paper, after which the paper was placed in a ventilated place at room temperature for $3 \mathrm{~h}$ to evaporate the water in the urine; method 2: The water in urine was removed under a gentle $\mathrm{N}_{2}$ stream at $40{ }^{\circ} \mathrm{C}$, and the dried residue was re-dissolved in methanol containing an internal standard. The methanol solution was dropped on $\mathrm{Na}_{2} \mathrm{SO}_{4}$ impregnated paper.

\section{Results and discussion}

\subsection{Monosaccharides and disaccharides alkali metal adduct ions by SIPS-MS}

In a typical experiment, a triangular piece of chromatography paper was dipped into an aqueous alkali salt solution $\left(\mathrm{Li}_{2} \mathrm{SO}_{4}, \mathrm{Na}_{2} \mathrm{SO}_{4}, \mathrm{~K}_{2} \mathrm{SO}_{4}\right.$, $\mathrm{Rb}_{2} \mathrm{SO}_{4}, \mathrm{Cs}_{2} \mathrm{SO}_{4}$ or a mixture thereof). As shown in Fig. S1, when the concentration of $\mathrm{Na}_{2} \mathrm{SO}_{4}$ was higher than $0.01 \mathrm{~mol} \mathrm{~L}^{-1}$, interference peaks with salt cluster signals, i.e. $m / z 165,307,449,591,733$, and 875 , occurred. When the salt concentration was $0.01 \mathrm{~mol} \mathrm{~L}^{-1}$ or lower, the interference peak of the salt cluster signal almost disappeared. Besides, the salt concentration also affects the MS intensity of metal adduct ions; although the MS intensity of $0.005 \mathrm{~mol} \mathrm{~L}^{-1} \mathrm{Na}_{2} \mathrm{SO}_{4}$ was slightly higher than that of $0.01 \mathrm{~mol} \mathrm{~L} \mathrm{~L}^{-1}$, for $\mathrm{K}_{2} \mathrm{SO}_{4}, \mathrm{Rb}_{2} \mathrm{SO}_{4}$, and $\mathrm{Cs}_{2} \mathrm{SO}_{4}$, $0.01 \mathrm{~mol} \mathrm{~L}^{-1}$ had a higher MS intensity than $0.005 \mathrm{~mol} \mathrm{~L}^{-1}$ (not given here). Therefore, $0.01 \mathrm{~mol} \mathrm{~L}^{-1}$ was selected as the concentration for the five alkali salt solutions after comprehensive consideration, which ensured overall less MS background interference as well as a relative high MS intensity. Alkali metal salt-impregnated paper was dried after its preparation (see section 2.4), and placed on a home-made XYZR moving plate for accurately positioning the paper tip relative to the MS cone. Then $15 \mu \mathrm{L}$ of sample solution (in methanol) was dropped onto the paper substrate, after which a voltage of $+3.5 \mathrm{kV}$ was applied for PSMS analysis [21].

For monosaccharides and disaccharides we selected ribose, fructose, and maltose as model compounds ( $5 \mu \mathrm{g} \mathrm{mL}{ }^{-1}$ in methanol), and a lowresolution nominal mass MS was used to most directly show proof of principle. The alkali metal adduct ions yielded the only abundant signal on different alkali metal salt-impregnated paper, i.e. $[\mathrm{M}+\mathrm{Li}]^{+}$, $[\mathrm{M}+\mathrm{Na}]^{+}, \quad[\mathrm{M}+\mathrm{K}]^{+}, \quad[\mathrm{M}+\mathrm{Rb}]^{+}, \quad$ and $[\mathrm{M}+\mathrm{Cs}]^{+}, \quad$ i.e. $m / z$ : [ribose $+\mathrm{Li}^{+}=157,\left[\right.$ ribose $+\mathrm{Na}^{+}=173$, [ribose $+\mathrm{K}^{+}=189, \quad[\text { ribose }+\mathrm{Rb}]^{+}=235$,

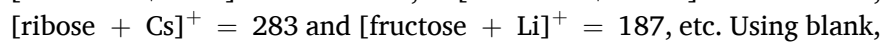
untreated paper, there is no $[\mathrm{M}+\mathrm{H}]^{+}$signal and only a small $[\mathrm{M}+\mathrm{Na}]^{+}$ signal, resulting from the naturally occurring, low $\mathrm{Na}^{+}$content in the paper matrix. Compared with the blank paper, the signal-to-noise ratio 
(S/N) increased by almost two orders of magnitude. The absolute abundance of alkali metal adduct ions generally follow the order: $\mathrm{Li}^{+}>\mathrm{Na}+>\mathrm{K}^{+}>\mathrm{Rb}^{+}>\mathrm{Cs}^{+}$(see Fig. 1). This suggests that stronger affinities of the alkali metal ions to glycans lead to higher signals. It is coincident with that reported in reference [22].

We also selected flavone glycosides (rutin) and quercetin, a typical polyphenol aglycone, and these were also ionized on an alkali metal saltimpregnated paper. It was found that the ionization of quercetin was very poor under these conditions (see Fig. S2 \& Table S2) and almost no alkali metal adduct ions were observed; in sharp contrast, the rutin showed the same good alkali metal adduction and ionization characteristics, confirming the high structure selectivity in the ionization on the salt-impregnated substrate for glycans and glycoconjugates.

\subsection{Linear oligosaccharides and cyclic glycans alkali metal adduct ions by SIPS-MS}

To investigate the ionization ability of alkali metal salt-impregnated paper to oligosaccharides, we used maltose oligosaccharides (up to maltoheptaose; degree of polymerization (DP) 1-7) and neoagarobiose oligosaccharides with DP 8-10; mass range to 1549) as model compounds on such 'five salts'-impregnated paper. For the whole series a high abundance of alkali metal adduct ions could be produced. For DP1DP6, we obtained $[\mathrm{M}+\mathrm{Li}]^{+},[\mathrm{M}+\mathrm{Na}]^{+},[\mathrm{M}+\mathrm{K}]^{+},[\mathrm{M}+\mathrm{Rb}]^{+}$and $[\mathrm{M}+\mathrm{Cs}]^{+}$(see Fig. S3-1 of taking DP-4 as an example). From DP7 onwards, also $[\mathrm{M}+2 \mathrm{Li}]^{2+},[\mathrm{M}+2 \mathrm{Na}]^{2+},[\mathrm{M}+2 \mathrm{~K}]^{2+},[\mathrm{M}+2 \mathrm{Rb}]^{2+}$ and $[\mathrm{M}+2 \mathrm{Cs}]^{2+}$ were observed (see Fig. S3-2 of taking DP-9 as an example). This formation of multi-charged ions is very useful for the MS analysis of oligo- and polysaccharides which thus easily stay within the optimal detection range of even standard mass spectra.

SIPS-MS analysis of cyclic glycans $\alpha$-, $\beta$ - and $\gamma$-cyclodextrin (5 $\mu \mathrm{g} \mathrm{mL} \mathrm{mL}^{-1}$ in $1 / 1$ methanol/ $\mathrm{H}_{2} \mathrm{O}$ ) also shows a high abundance of alkali metal adduct ions with some clear trends (see Fig. S4 of taking $\beta$-cyclodextrin as an example). First, from the absolute abundance of $[\mathrm{M}+\mathrm{Li}]^{+},[\mathrm{M}+\mathrm{Na}]^{+},[\mathrm{M}+\mathrm{K}]^{+},[\mathrm{M}+\mathrm{Rb}]^{+},[\mathrm{M}+\mathrm{Cs}]^{+}, \alpha$-cyclodextrin shows the strongest metal affinity (see Table S2). Second, $[\mathrm{M}+\mathrm{K}]^{+}$, $[\mathrm{M}+\mathrm{Rb}]^{+}$and $[\mathrm{M}+\mathrm{Cs}]^{+}$signals from single-metal impregnated paper are often accompanied by $[\mathrm{M}+\mathrm{Na}]^{+}$signals, which are produced from low content $\mathrm{Na}^{+}$ions always present in the paper matrix. This $[\mathrm{M}+\mathrm{Na}]^{+}$ signal is especially intense in the spectrum of cesium-impregnated paper, which is more obvious than in linear glycans (see Figs. 1 and 2 the $\mathrm{Cs}_{2} \mathrm{SO}_{4}$ spectrum). This implies that for these cyclic structures the differences of affinities to various metals are even stronger. Third, when using a $120 \mathrm{~V}$ cone voltage on five mixed salt-impregnated paper, collision-induced dissociation (CID) of $[\alpha \text {-cyclodextrin }+ \text { met }]^{+}$were shown in Fig. $3 \alpha$-cyclodextrin continuously eliminated anhydrous

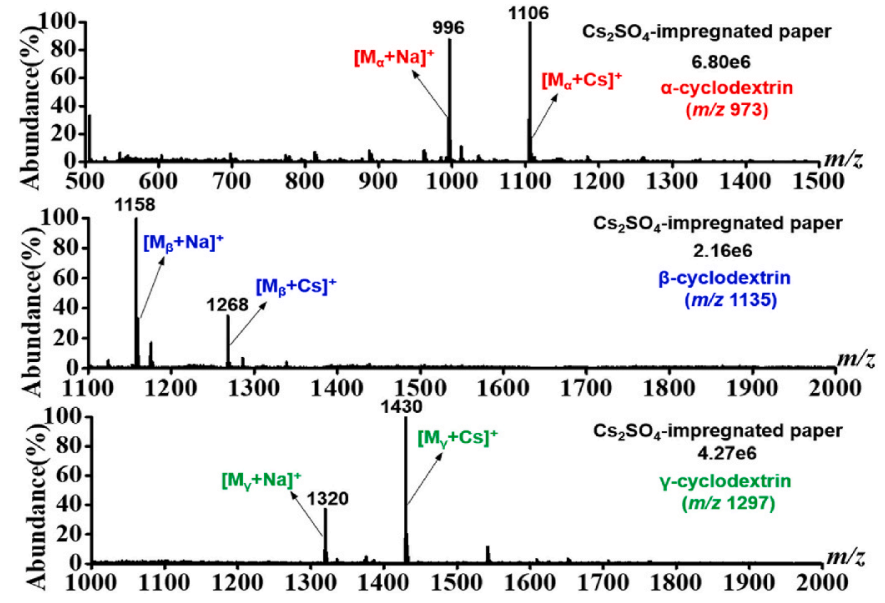

Fig. 2. Typical mass spectra for $\alpha$-, $\beta$-, $\gamma$-cyclodextrin on $\mathrm{Cs}_{2} \mathrm{SO}_{4}$-impregnated paper. $\mathbf{M}_{\alpha}, \mathrm{M}_{\beta}$ and $\mathrm{M}_{\gamma}$ are the relative molecular masses of $\alpha$-cyclodextrin, $\beta$-cyclodextrin and $\gamma$-cyclodextrin respectively.

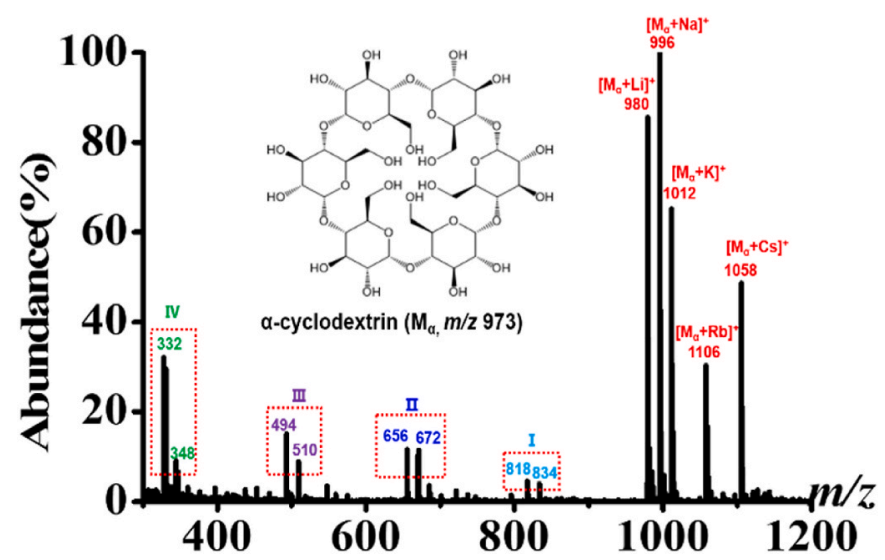

Fig. 3. Paper spray mass spectrum for $\alpha$-cyclodextrin on five mixed saltimpregnated paper by employing a $120 \mathrm{~V}$ cone voltage. $\mathrm{M}_{\alpha}$ is the relative molecular masses of $\alpha$-cyclodextrin. I, II, III and corresponding to the sequential elimination of an anhydroglucose unit $(\Delta m / z=162)$, two anhydroglucose units $(2 \Delta m / z=324)$, three anhydroglucose units $(3 \Delta m / z=486)$, and four anhydro -glucose units $(4 \Delta m / z=648)$, respectively.
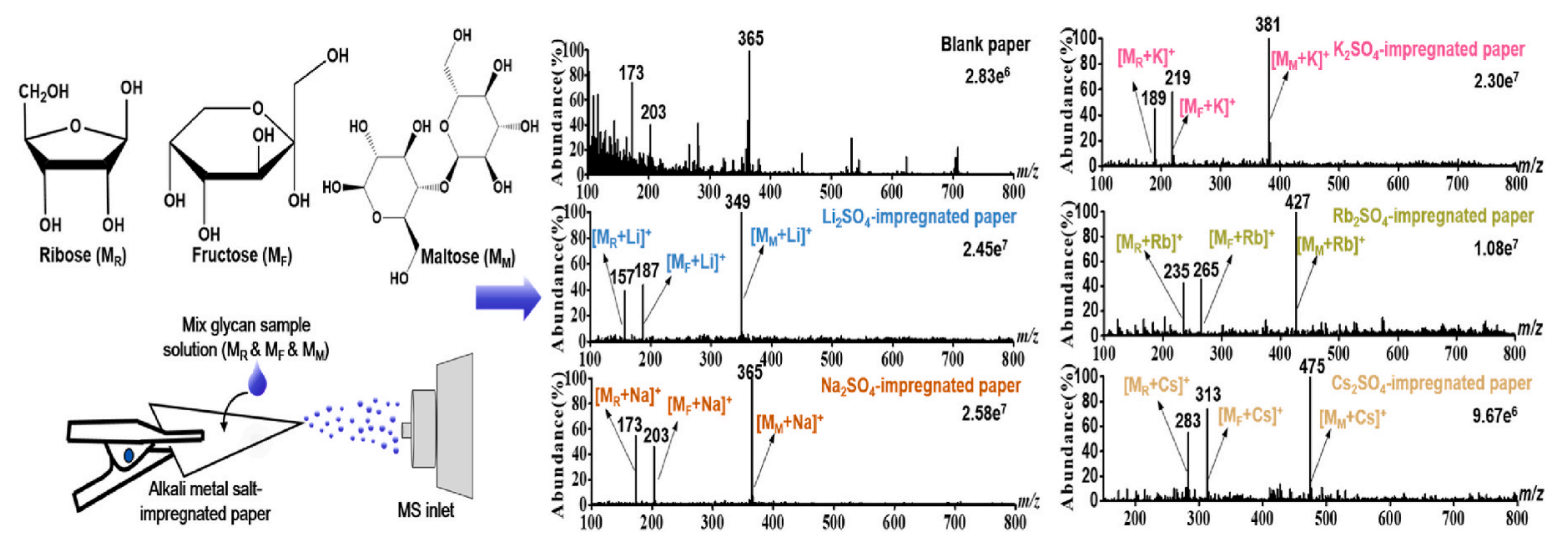

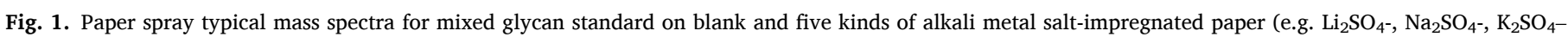

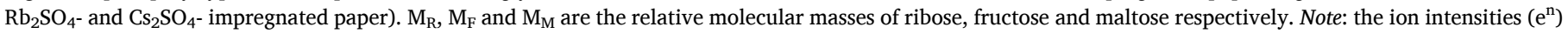
represent the absolute abundance values of the peak with the highest ion intensity. 
glucose units [23] and different metal adducts also displayed analogous fragmentation modes. As a result, we can effectively obtain abundant fragment information at the same time.

\subsection{Determination of molecular weight of mixed glycans by SIPS-MS}

When analyzing by SIPS-MS a mixed standard solution containing known three glycans (ribose, fructose and maltose) using a 'five-salt'impregnated paper simultaneously containing equal amounts of $\mathrm{Li}^{+}$, $\mathrm{Na}^{+}, \mathrm{K}^{+}, \mathrm{Rb}^{+}$, and $\mathrm{Cs}^{+}$salts in one paper, the mass spectrum displays fifteen clear main peaks, and they are easily divided into three categories (see Fig. 4). Specifically, $m / z$ 157, 173, 189, 235, and 283, corresponds to the $[\mathrm{M}+\mathrm{Li}]^{+},[\mathrm{M}+\mathrm{Na}]^{+},[\mathrm{M}+\mathrm{K}]^{+},[\mathrm{M}+\mathrm{Rb}]+$ and $[\mathrm{M}+\mathrm{Cs}]+$ peaks of ribose, respectively; $m / z 187,203,219,265$, and 313 corresponds to $[\mathrm{M}+\mathrm{Li}]^{+},[\mathrm{M}+\mathrm{Na}]^{+},[\mathrm{M}+\mathrm{K}]^{+},[\mathrm{M}+\mathrm{Rb}]^{+}$and $[\mathrm{M}+\mathrm{Cs}]^{+}$of fructose, respectively; $m / z 349,365,381,427$, and 475 corresponds to $[\mathrm{M}+\mathrm{Li}]^{+},[\mathrm{M}+\mathrm{Na}]^{+},[\mathrm{M}+\mathrm{K}]^{+},[\mathrm{M}+\mathrm{Rb}]^{+}$and $[\mathrm{M}+\mathrm{Cs}]^{+}$of maltose, respectively. The results again reflect the difference in affinity of glycans towards different alkali metal ions, and the molecular weight difference can also help in determining the molecular weight of unknown glycans.

\subsection{Investigation of structural affinity domain of glycans towards alkali metal ions}

From the analyses of linear and cyclic glycans, it is thus found that the alkali metal ion adduction is highly sensitive towards the detection of glycan structures. In order to investigate the structural basis of the affinity of glycans with alkali metal ions on salt-impregnated paper, we investigated different compounds with trans-pinacol, cis-pinacol and 2hydroxymethyl -tetrahydropyran structure domains. As characteristic examples ethylene glycol, glycerol, cis-1,2-cyclohexanediol, trans-1,2cyclohexanediol and tetrahydropyran-2-methanol were used for SIPSMS. The results showed that there was almost no alkali metal adduction to trans-pinacol, however, ethylene glycol, glycerol, cis-pinacol and 2-hydroxymethyl-tetrahydropyran structure domains displayed a high affinity to alkali metal ions (see Fig. S5 \& Table S2).

In addition, such structure-dependent differences were also observed in more complex glycans, like 3-fucosyllactose and 2 '-fucosyllactose (see Fig. 5a and b \& Table S2), two typical human milk oligosaccharides. Surprisingly, 3-fucosyllactose formed abundant $[\mathrm{M}+\mathrm{Li}]^{+},[\mathrm{M}+\mathrm{Na}]^{+}$, $[\mathrm{M}+\mathrm{K}]^{+},[\mathrm{M}+\mathrm{Rb}]^{+},[\mathrm{M}+\mathrm{Cs}]^{+}$adducts, while $2^{\prime}$-fucosyllactose did not. To investigate the difference, we calculated the affinity of 3-fucosyllactose and $2^{\prime}$-fucosyllactose to $\mathrm{Na}^{+}$by B3LYP and wB97XD density

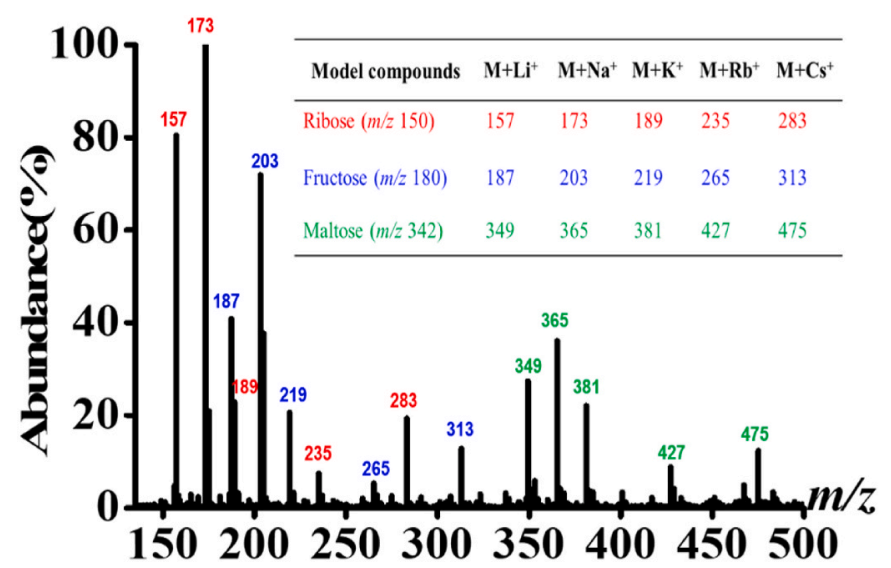

Fig. 4. Paper spray mass spectrum for glycans-mixed standard (ribose, fructose and maltose) on five mixed salt-impregnated paper. Note: Red, blue, and green labelled correspond to the five characteristic peaks $\left(\mathrm{Li}^{+}, \mathrm{Na}^{+}, \mathrm{K}^{+}, \mathrm{Rb}^{+}\right.$, and $\mathrm{Cs}^{+}$) of ribose, fructose and maltose, respectively. (For interpretation of the references to colour in this figure legend, the reader is referred to the Web version of this article.) functional theory calculations 6-311 $+\mathrm{G}(\mathrm{d})$ basis set with basis set superposition error correction (All computations were performed with the Gaussian 16 suite of programs, with the B3LYP and wB97XD functionals as implemented in there; a 6-311 + G (d,p) basis set was used throughout, and complexation energies were corrected using a basis set superposition error, which typically was on the order of $1 \mathrm{kcal} / \mathrm{mol}$. The electrostatic potential map was generated using Gaussview 6). These results were showed in Fig. $5 \mathrm{c}$ and d, the electrostatic potential surface of both sugarswas calculated was calculated, and then the $\mathrm{Na}^{+}$ion was placed at several positions of high negative potential, after which the [glycan $+\mathrm{Na}]^{+}$adduct structures were optimized. Independent of the method, [3-fucosyllactose $+\mathrm{Na}^{+}$was found to be $\sim 7 \mathrm{kcal} / \mathrm{mol}$ more stable than $\left[2^{\prime} \text {-fucosyllactose }+\mathrm{Na}\right]^{+}$. Detailed investigation shows this may be due to subtle differences in the $\mathrm{Na}^{+}$binding; for example, the three shortest $\mathrm{Na}$..O distances in [3-fucosyllactose $+\mathrm{Na}{ }^{+}$average out to $2.258 \pm 0.042 \AA$, while in $\left[2^{\prime} \text {-fucosyllactose }+\mathrm{Na}\right]^{+}$this is $2.339 \pm 0.080 \AA$. This computational result agrees with the experimental finding that 3-fucosyllactose can easily form $\mathrm{Na}^{+}$adducts, while 2 '-fucosyllactose cannot, and highlights the structural sensitivity of SIPS-MS.

\subsection{Application of SIPS-MS to analysis of glycans in complicated matrices}

In order to investigate the specificity and anti-interference ability of glycan and glycoconjugate ionization by SIPS-MS, complicated matrices including Panax ginseng extracts, Codonopsis pilosula extracts, honey, dry blood spots and urine were tested.

\subsubsection{Application to plant extracts}

Glycans and glycoconjugates are normal natural and bio-active components in plants. Codonopsis pilosula is a perennial species of flowering plant in the bellflower family, and an extract was obtained via ultrasonication in methanol/water (80/20). There are six MS peaks visible upon ionization from blank paper: $m / z 203,219,381,399,543$, and 705 (see Fig. 6). Only based on these results, it is difficult to ascertain the molecular weight of any component. However, from different salt-impregnated papers, there are 5 strong response peaks corresponding to the $\mathrm{Li}^{+} \sim \mathrm{Cs}{ }^{+}$adduction ions (see Fig. 6). Therefore, the molecular weight can be quickly and accurately calculated to 180 , $342,360,504$ and 666, respectively which corresponding to glucose (or fructose), maltose (or sucrose), D-mannose, raffinose and stachyose.

Panax ginseng extract contains a variety of ginsenosides. The PS-MS profile of ginsenosides in Panax ginseng extract from blank and saltimpregnated papers is given in Fig. S6. From blank paper, the abundance of ginsenosides is very low, and background signals almost submerge the ginsenosides responses. However, the abundance of alkali metal adduction ions significantly increases on the salt-impregnated papers, with a $\mathrm{S} / \mathrm{N}$ increase by almost 2 orders of magnitude. Depending on the regularities of the mass differences between the various alkali metal ions used, the molecular weight of the ginsenosides can be easily calculated, i.e. 639, 771, 785, 801, 947 and 1079, respectively. These molecular masses are consistent with the values of ginsenosides determined in Refs. [24,25].

\subsubsection{Application in honey adulteration}

Honey gets its sweetness from the monosaccharides fructose and glucose, and has about the same relative sweetness as sucrose. Since the latter is much cheaper to obtained, adulteration of honey is nearly always caused by addition of sucrose. Quality control of honey thus involves the monitoring of fructose, glucose, and sucrose. Our SIPS-MS approach can rapidly analyze the sugar in honey samples. A typical mass spectrum of salt-impregnated paper spray MS of sucrose-adulterated honey is given in Fig. 7a. The $[\mathrm{M}+\mathrm{Na}]^{+}$of fructose and glucose $(\mathrm{m} / \mathrm{z}$ 203 ) is clearly displayed on NaCl-impregnated paper spray MS, and the added sucrose can be observed from the $[\text { sucrose }+\mathrm{Na}]^{+}$peak $(\mathrm{m} / \mathrm{z}$ 


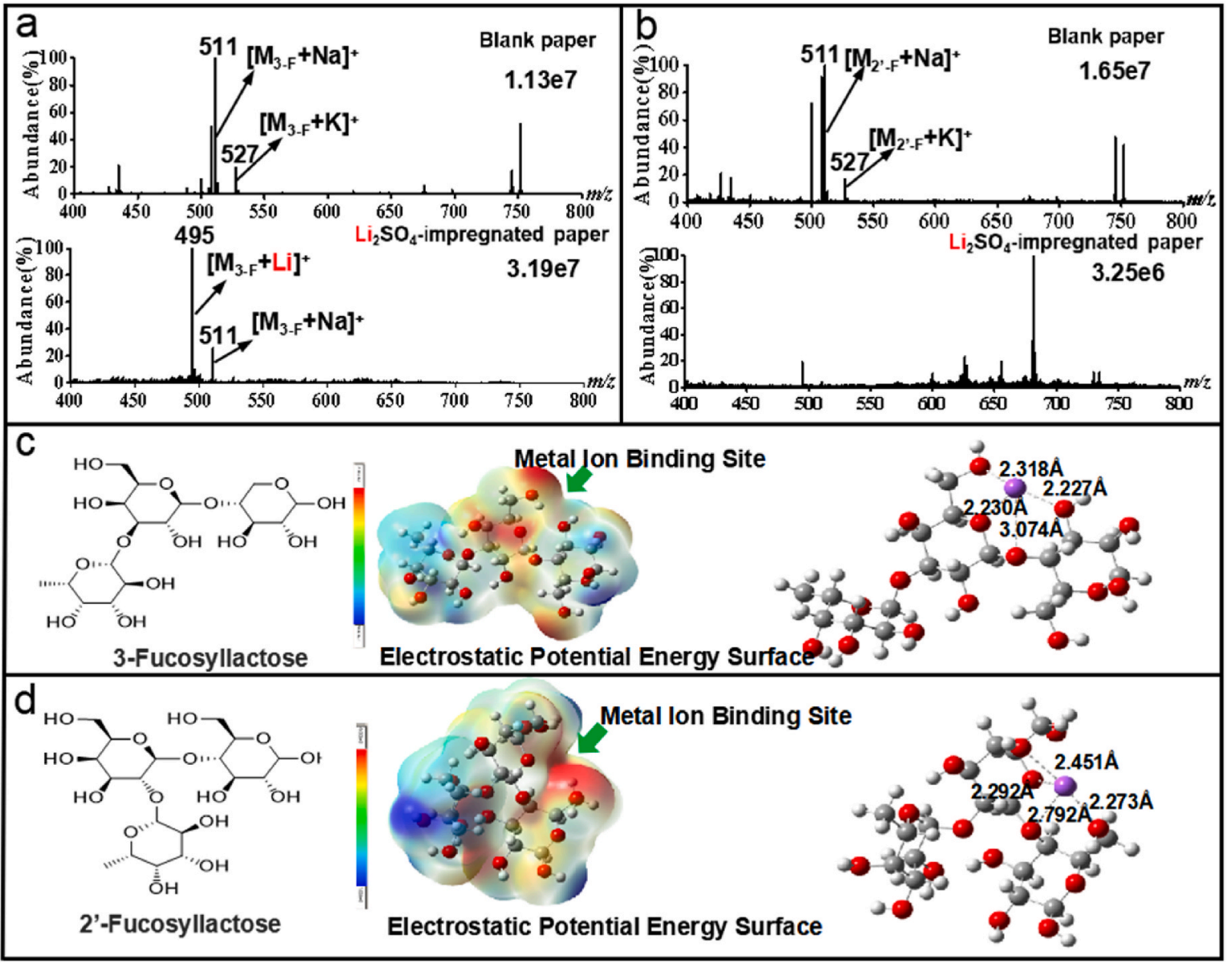

Fig. 5. Paper spray mass spectra on blank and $\mathrm{Li}_{2} \mathrm{SO}_{4}$-impregnated paper for 3-fucosyllactose (a) and $2^{\prime}$-fucosyllactose (b). Structure, electrostatic potential energy surface and possible $\mathrm{Na}^{+}$-coordinated conformers of 3-fucosyllactose (c) and 2'-fucosyllactose (d). $\mathrm{M}_{3-\mathrm{F}}$ and $\mathrm{M}_{2}{ }^{\prime}-\mathrm{F}$ are the relative molecular masses of 3-fucosyllactose $(\mathrm{m} / \mathrm{z} 488)$ and $2^{\prime}$-fucosyllactose $(\mathrm{m} / \mathrm{z} 488)$, respectively.
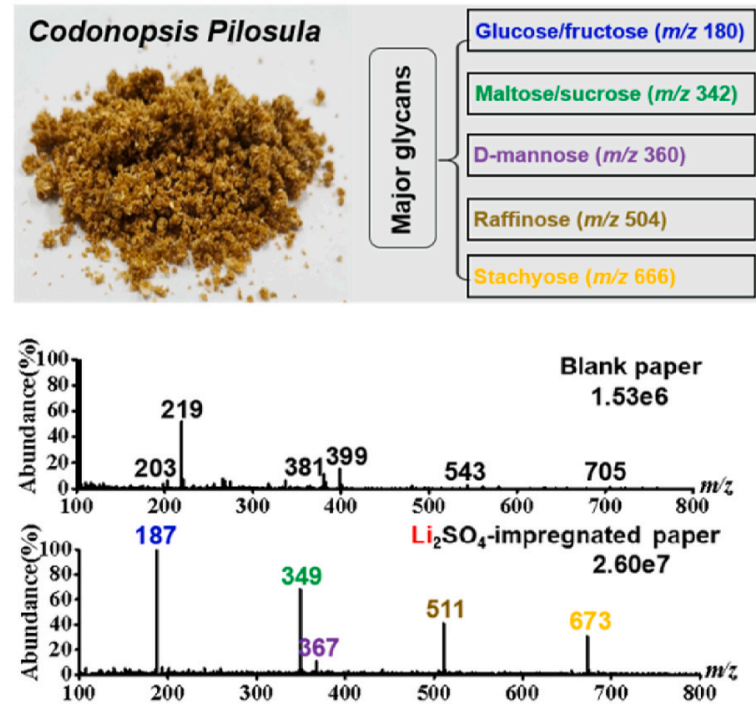
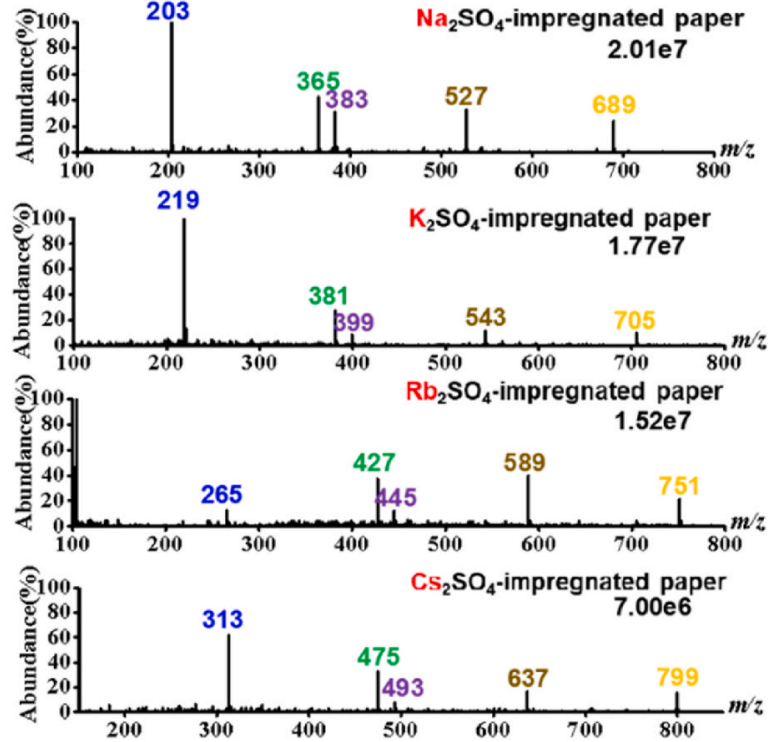

Fig. 6. Paper spray mass spectra for Codonopsis Pilosula extracts on blank and five kinds of alkali metal salt-impregnated paper.

365). Unadulterated honey does not display such sucrose-derived peaks in SIPS-MS.

\subsubsection{Application in blood and urine samples}

The levels of blood sugars, primarily glucose, are important indicators for the diagnosis of diabetes, and are in healthy individuals kept within a narrow range. For salt-impregnated paper spray MS analysis, 


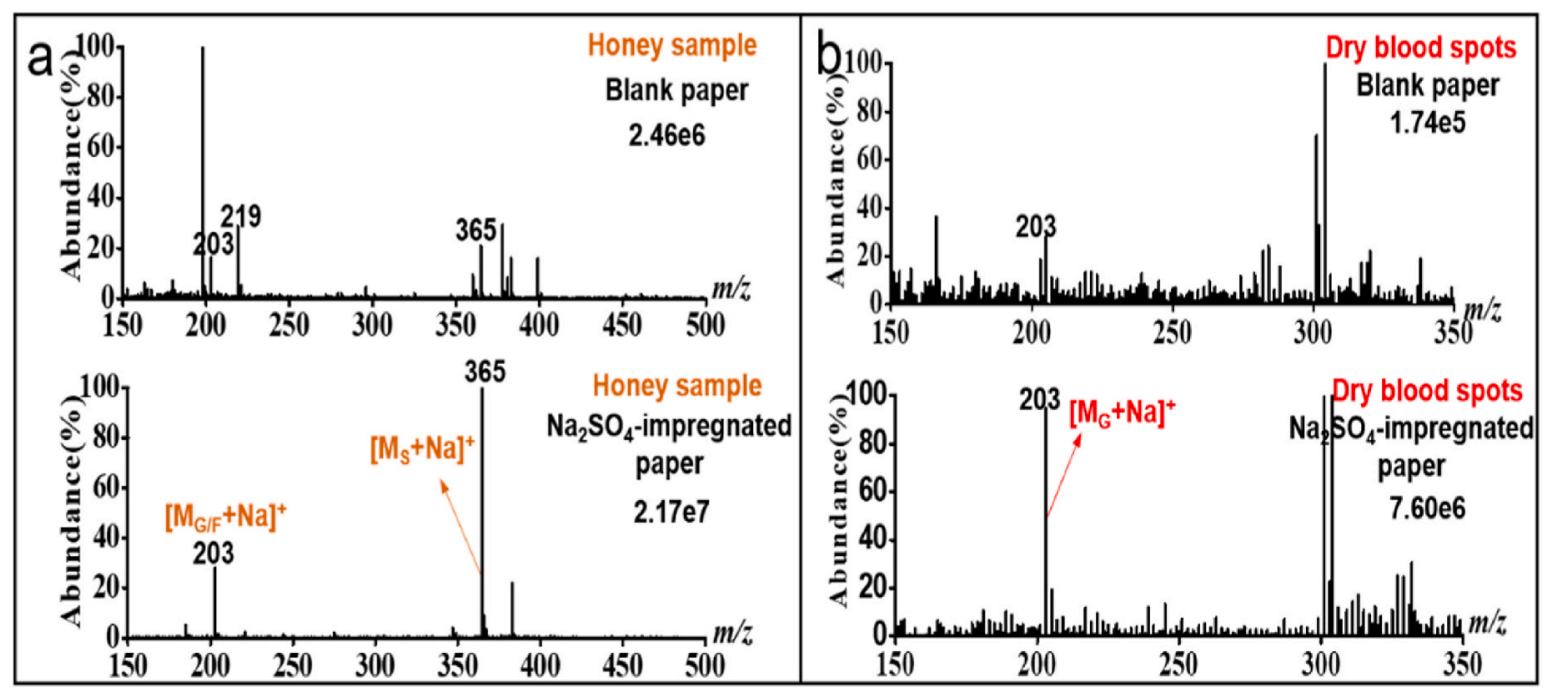

Fig. 7. Paper spray mass spectra for honey (a) and dry blood spots (b) on blank and $\mathrm{Na}_{2} \mathrm{SO}_{4}$-impregnated paper. $\mathrm{M}_{\mathrm{G} / \mathrm{F}}, \mathrm{M}_{\mathrm{S}}$ and $\mathrm{M}_{\mathrm{G}}$ are the relative molecular masses of glucose/fructose, sucrose and glucose, respectively.

the glucose ionization ([glucose $+\mathrm{Na}]^{+}, m / z$ 203) is effective although there is high content of protein and salt in samples (see Fig. 7b). In standard MS analyses the existence of multi ion forms such as $[\mathrm{M}+\mathrm{H}]^{+}$, $[\mathrm{M}+\mathrm{Na}]^{+},[\mathrm{M}+\mathrm{K}]^{+}$etc. is very unfavorable for the accurate quantitative analysis. However, when glycans and glycoconjugates are analyzed by SIPS-MS, a single alkali metal adduction ion (especially on Na impregnated paper) is present, because of high content of salt in the paper matrix, which is very beneficial for accurate quantitative analysis.

To this end, we used $\mathrm{Na}_{2} \mathrm{SO}_{4}$-impregnated paper to quantitatively analyze glucose in undiluted urine samples ((see method 1 of preparation of urine samples). When directly dropping urine on blank or $\mathrm{Na}_{2} \mathrm{SO}_{4}$-impregnated paper to be analyzed, primarily a large number of water cluster ions was observed that have a mass difference of 18 (e.g. $m / z 221,239,257,275$, et., see Fig. S7a). Therefore, a simple pretreatment was employed, i.e. the water in urine was removed under a gentle $\mathrm{N}_{2}$ stream at $40{ }^{\circ} \mathrm{C}$, and the dried residue was re-dissolved in methanol containing an internal standard (see method 2 of preparation of urine samples), which presented a clean mass characterized peak [glucose $+\mathrm{Na}^{+}, m / z$ 203] (see Fig. S7b). The methanol solution was dropped on $\mathrm{Na}_{2} \mathrm{SO}_{4}$-impregnated paper, and analyzed by SIPS-MS. Using ribose as internal standard, a calibration curve was constructed through the abundance ratios of [glucose $+\mathrm{Na}^{+}$to [ribose $\left.+\mathrm{Na}\right]^{+}$ vs. concentration of glucose. The linearity range was 10-150 $\mu \mathrm{g} \mathrm{mL} \mathrm{mL}^{-1}\left(\mathrm{R}^{2}=0.9995\right)$ (see Fig. S8). The limit of detection (LOD) and limit of quantification (LOQ) were $1.0 \mu \mathrm{g} \mathrm{mL}^{-1}$ and $3.0 \mu \mathrm{g} \mathrm{mL}^{-1}$, respectively; the RSD is $4.2-7.5 \%$ and the recovery of glucose was $98.2,101.4,105.3 \%$ at $10,50,120 \mu \mathrm{mL}^{-1}$, respectively. These results show SIPS-MS displays both good linearity and reproducibility. This is in stark contrast with paper spray analysis of glucose in urine using blank paper, which is basically impossible because of small signals and highly complicated background signals. Furthermore, limits of detection (LODs, $\mathrm{S} / \mathrm{N}=3$ ) and limits of quantification (LOQs, $\mathrm{S} / \mathrm{N}=10$ ) of target compounds in five different matrices, such as Panax ginseng extracts, Codonopsis pilosula extracts, honey, dry blood spots and urine by SIPS-MS (using $\mathrm{Na}_{2} \mathrm{SO}_{4}$-impregnated paper) and PS-MS (using blank paper) (see Table 1). Compared with the PS-MS of using blank paper, the LODs and LOQs of most target compounds increased almost one orders of magnitude by SIPS-MS of using $\mathrm{Na}_{2} \mathrm{SO}_{4}$-impregnated paper. These results indicate the strong potential of SIPS-MS towards the analysis of real biological samples and tradition Chinese medicine extracts.

Table 1

Limits of detection (LODs, $\mathrm{S} / \mathrm{N}=3$ ) and limits of quantification (LOQs, $\mathrm{S} / \mathrm{N}=10$ ) of target compounds in five different matrices, such as Panax ginseng extracts, Codonopsis pilosula extracts, honey, dry blood spots and urine by SIPS-MS (using $\mathrm{Na}_{2} \mathrm{SO}_{4}$-impregnated paper) and PS-MS (using blank paper).

\begin{tabular}{|c|c|c|c|c|c|c|c|}
\hline \multirow[t]{2}{*}{ Matrices } & \multirow{2}{*}{$\begin{array}{l}\text { Target } \\
\text { compounds }\end{array}$} & \multicolumn{3}{|l|}{ SIPS-MS } & \multicolumn{3}{|l|}{ PS-MS } \\
\hline & & $\begin{array}{l}\text { Characteristic } m / z \\
\text { values }\end{array}$ & $\begin{array}{l}\text { LODs }(\mu \mathrm{g} \\
\left.\mathrm{mL}^{-1}\right)\end{array}$ & $\begin{array}{l}\text { LOQs }(\mu \mathrm{g} \\
\left.\mathrm{mL}^{-1}\right)\end{array}$ & $\begin{array}{l}\text { Characteristic } m / z \\
\text { values }\end{array}$ & $\begin{array}{l}\text { LODs }(\mu \mathrm{g} \\
\left.\mathrm{mL}^{-1}\right)\end{array}$ & $\begin{array}{l}\text { LOQs }(\mu \mathrm{g} \\
\left.\mathrm{mL}^{-1}\right)\end{array}$ \\
\hline \multirow{6}{*}{$\begin{array}{l}\text { Plant extracts (Panax ginseng } \\
\text { extracts) }\end{array}$} & $\mathrm{Rh}_{1}$ & 662 & 1.0 & 3.0 & 662 & 10 & 30 \\
\hline & $\mathrm{F}_{3}$ & 794 & 2.0 & 5.0 & 794 & 15 & 45 \\
\hline & ${ }^{\mathrm{a}} \mathrm{Rg}_{2} / \mathrm{Rg}_{3}$ & 808 & 3.0 & 10.0 & ND & ND & ND \\
\hline & ${ }^{\mathrm{a}} \mathrm{Rg}_{1} / \mathrm{R}_{\mathrm{f}}$ & 824 & 0.8 & 2.5 & ND & ND & ND \\
\hline & ${ }^{\mathrm{a}} \mathrm{Re} / \mathrm{Rd}$ & 970 & 0.5 & 1.5 & 970 & 10 & 30 \\
\hline & ${ }^{\mathrm{a}} \mathrm{Rc} / \mathrm{Rb}_{2} / \mathrm{Rb}_{3}$ & 1102 & 1.0 & 3.0 & 1102 & 10 & 30 \\
\hline \multirow{6}{*}{$\begin{array}{l}\text { Plant extracts (Codonopsis pilosula } \\
\text { extracts) }\end{array}$} & ${ }^{\mathrm{a}}$ Glucose/ & 203 & 0.1 & 0.5 & 203 & 20 & 55 \\
\hline & Fructose & & & & & & \\
\hline & $\begin{array}{l}{ }^{\mathrm{a}} \text { Maltose/ } \\
\text { Sucrose }\end{array}$ & 365 & 0.3 & 1.0 & 381 & 15 & 40 \\
\hline & D-mannose & 383 & 1.0 & 4.0 & 399 & 20 & 60 \\
\hline & Raffinose & 527 & 0.5 & 1.5 & ND & ND & ND \\
\hline & Stachyose & 689 & 0.8 & 2.0 & ND & ND & ND \\
\hline Honey & Sucrose & 365 & 0.2 & 1.0 & 365 & 20 & 50 \\
\hline Dry blood spots & Glucose & 203 & 2.5 & 8.0 & 203 & 25 & 80 \\
\hline Urine & Glucose & 203 & 1.0 & 5.0 & 203 & 20 & 60 \\
\hline
\end{tabular}

Note: ${ }^{\text {a }}$ refers to isomers. ND, not detected by PS-MS method. 


\section{Conclusions}

In summary, the trivial impregnation of filter paper with alkali metal salts allows for the highly sensitive and specific detection of glycans by paper spray MS. The principle behind this salt-impregnated paper spray MS is the efficient formation of [Glycan $+\mathrm{Met}^{+}$adducts. Since larger oligosaccharides display adducts with multiple charges, this will also allow the analysis of large and complex oligosaccharides. Compared with other ambient MS methods, SIPS-MS is both trivial in its use, extremely low cost and much more sensitive towards glycans analysis. These results were already evident with a low-end mass spectrometer, which demonstrates proof of principle. As a result, this indicates great potential for the detection of trace glycans, especially when combined with ion mobility MS (to distinguish isomers) [26] and multi-stage mass spectrometry.

\section{Credit author statement}

Ping Guo: Methodology, Investigation, Writing-Original draft preparation, Ke Min: Data curation, Software, Wei Luo \& Si Huang: Funding acquisition, Visualization, Zihui Yang \& Ming Ma: Supervision administration, Shubin Liu \& Zhengfa Fang: Validation, Bo Chen: WritingReviewing and Editing, Conceptualization, Han Zuilhof: Term, Conceptualization.

\section{Declaration of competing interest}

The authors declare that they have no known competing financial interests or personal relationships that could have appeared to influence the work reported in this paper.

\section{Acknowledgements}

The authors acknowledge support from the National Natural Science Foundation of China (21775040, 21775041, 21575040), the Aid Program for S\&T innovation research team in higher education institutions, the construction program of key disciplines of Hunan Province (2020SK2092, 2015JC1001), the Hunan Province 100 experts project.

\section{Appendix A. Supplementary data}

Supplementary data to this article can be found online at https://doi. org/10.1016/j.talanta.2021.122674.

\section{References}

[1] R.G. Cooks, Z. Ouyang, Z. Takats, J.M. Wiseman, Ambient mass spectrometry, Science 311 (2006) 1566-1570.

[2] T.H. Kuo, E.P. Dutkiewicz, J. Pei, C.C. Hsu, Ambient ionization mass spectrometry today and tomorrow: embracing challenges and opportunities, Anal. Chem. 92 (2020) 2353-2363.
[3] H. Wang, J. Liu, R.G. Cooks, Z. Ouyang, Paper spray for direct analysis of complex mixtures using mass spectrometry, Angew. Chem. Int. Ed. 49 (2010) 877-880.

[4] VeriSpray paper spray ion source-mass spectrometry, (Thermo Fisher Scientific Co.) https://www.thermofisher.com/cn/zh/home/industrial/mass-spectrom etry/liquid-chromatograp hy-mass-spectrometry-lc-ms/lc-m s-accessories/verispray-paperspray-ion-source-mass-spectro metry.html (accessed April 7, 2021).

[5] R. Narayanan, D. Sarkar, R.G. Cooks, T. Pradeep, Molecular ionization from carbon nanotube paper, Angew. Chem. Int. Ed. 53 (2014) 5936-5940.

[6] M. Wleklinski, Y. Li, S. Bag, D. Sarkar, R. Narayanan, T. Pradeep, R.G. Cooks, Zero volt paper spray ionization and its mechanism, Anal. Chem. 87 (2015) 6786-6793.

[7] Y. Ren, H. Wang, J. Liu, Z. Zhang, M.N. McLuckey, Z. Ouyang, Analysis of biological samples using paper spray mass spectrometry: an investigation of impacts by the substrates, solvents and elution methods, Chromatographia 76 (2013) 1339-1346.

[8] Y. Zheng, X. Zhang, H. Yang, X. Liu, X. Zhang, Q. Wang, Z. Zhang, Facile preparation of paper substrates coated with different materials and their applications in paper spray mass spectrometry, Anal. Methods. 7 (2015) 5381-5386.

[9] D. Kim, U.H. Yim, B. Kim, S. Cha, S. Kim, Paper spray chemical ionization: highly sensitive ambient ionization method for low- and nonpolar aromatic compounds, Anal. Chem. 89 (2017) 9056-9906.

[10] J. Liu, Y. He, S. Chen, M. Ma, S. Yao, B. Chen, New urea-modified paper substrate for enhanced analytical performance of negative ion mode paper spray mass spectrometry, Talanta 166 (2017) 306-314.

[11] T. Zargar, T. Khayamian, M.T. Jafari, Immobilized aptamer paper spray ionization source for ion mobility spectrometry, J. Pharmaceut. Biomed. Anal. 132 (2017) 232-237.

[12] S. Chiang, W. Zhang, Z. Ouyang, Paper spray ionization mass spectrometry: recent advances and clinical applications, Expert Rev. Proteomics 15 (2018) 781-791.

[13] S. Huang, F.W. Claassen, T.A. van Beek, B. Chen, J. Zeng, H. Zuilhof, G.I. Salentijn, Rapid distinction and semiquantitative analysis of THC and CBD by silverimpregnated paper spray mass spectrometry, Anal. Chem. 93 (2021) 3794-3802.

[14] J.I. Zhang, X. Li, Z. Ouyang, R.G. Cooks, Direct analysis of steviolglycosides from Stevia leaves by ambient ionization mass spectrometry performed on whole leaves, Analyst 137 (2012) 3091-3098.

[15] Y. Wang, L. Liu, L. Ma, S. Liu, Identification of saccharides by using direct analysis in real time (DART) mass spectrometry, Int. J. Mass Spectrom. 357 (2014) 51-57.

[16] H. Chen, I. Cotterodríguez, R.G. Cooks, cis-Diol functional group recognition by reactive desorption electrospray ionization (DESI), Chem. Commun. 6 (2006) 597-599.

[17] P.M. Peacock, W.J. Zhang, S. Trimpin, Advances in ionization for mass spectrometry, Anal. Chem. 89 (2017) 372-388.

[18] B.D. Davis, J.S. Brodbelt, Determination of the glycosylation site of flavonoid monoglucosides by metal complexation and tandem mass spectrometry, J. Am. Soc. Mass Spectrom. 15 (2004) 1287-1299.

[19] T.J. Kauppila, N. Talaty, A.U. Jackson, T. Kotiaho, R. Kostiainen, R.G. Cooks, Carbohydrate and steroid analysis by desorption electrospray ionization mass spectrometry, Chem. Commun. 23 (2008) 2674-2676.

[20] A.U. Jackson, N. Talaty, R.G. Cooks, G.J. Van Berkel, Salt tolerance of desorption electrospray ionization (DESI), J. Am. Soc. Mass Spectrom. 18 (2007) 2218-2225.

[21] J.J. Liu, N.E. Manicke, X.Y. Zhou, R.G. Cooks, Z. Ouyang, Paper spray. Ambient Ionization Mass Spectrometry, 2014, pp. 389-422 (Chapter 16).

[22] E.I. Calixte, O.T. Liyanage, H.J. Kim, E.D. Ziperman, A.J. Pearson, E.S. Gallagher, Release of carbohydrate metal adducts from electrospray droplets: insight into glycan ionization by electrospray, J. Phys. Chem. B 124 (2020) 479-486.

[23] K.P. Madhusudanan, Multiple lithium exchange under lithium cationization of cyclod-extrins, J. Mass Spectrom. 38 (2003) 409-416.

[24] B.K. Shin, S.W. Kwon, J.H. Park, Chemical diversity of ginseng saponins from Panax ginseng, J. Ginseng Res. 39 (2015) 287-298.

[25] W.W. Ru, D.L. Wang, Y.P. Xu, X.X. He, Chemical constituents and bioactivities of Panax ginseng (C. A. Mey.), Drug Discoveries Ther 9 (2015) 23-32.

[26] O.J. Plante, E.R. Palmacci, P.H. Seeberger, Automated solid-phase synthesis of oligosaccharides, Science 291 (2001) 1523-1527. 